\title{
High-mobility group box 1 impairs airway epithelial barrier function through the activation of the RAGE/ERK pathway
}

\author{
WUFENG HUANG $^{1^{*}}$, HAIJIN ZHAO ${ }^{1 *}$, HANGMING DONG $^{1}$, YUE WU $^{1}$, \\ LIHONG YAO $^{1}$, FEI ZOU ${ }^{2}$ and SHAOXI CAI ${ }^{1}$ \\ ${ }^{1}$ Chronic Airways Diseases Laboratory, Department of Respiratory and Critical Care Medicine, \\ Nanfang Hospital, Southern Medical University; ${ }^{2}$ School of Public Health and Tropical Medicine, \\ Southern Medical University, Guangzhou, Guangdong 510515, P.R. China
}

Received December 4, 2015; Accepted March 2, 2016

DOI: $10.3892 /$ ijmm.2016.2537

\begin{abstract}
Recent studies have indicated that high-mobility group box 1 protein (HMGB1) and the receptor for advanced glycation end-products (RAGE) contribute to the pathogenesis of asthma. However, whether the activation of the HMGB1/RAGE axis mediates airway epithelial barrier dysfunction remains unknown. Thus, the aim of this study was to examine the effects of HMGB1 and its synergistic action with interleukin (IL)-1 $\beta$ on airway epithelial barrier properties. We evaluated the effects of recombinant human HMGB1 alone or in combination with IL-1 $\beta$ on ionic and macromolecular barrier permeability, by culturing air-liquid interface $16 \mathrm{HBE}$ cells with HMGB1 to mimic the differentiated epithelium. Western blot analysis and immunofluorescence staining were utilized to examine the level and structure of major junction proteins, namely E-cadherin, $\beta$-catenin, occludin and claudin-1. Furthermore, we examined the effects of RAGE neutralizing antibodies and mitogen-activated protein kinase (MAPK) inhibitors on epithelial barrier properties in order to elucidate the mechanisms involved. HMGB1 increased FITC-dextran permeability, but suppressed epithelial resistance in a doseand time-dependent manner. HMGB1-mediated barrier hyperpermeability was accompanied by a disruption of cellcell contacts, the selective downregulation of occludin and claudin-1, and the redistribution of E-cadherin and $\beta$-catenin. HMGB1 in synergy with IL-1 $\beta$ induced a similar, but greater
\end{abstract}

Correspondence to: Dr Shaoxi Cai, Chronic Airways Diseases Laboratory, Department of Respiratory and Critical Care Medicine, Nanfang Hospital, Southern Medical University, 1838 Guangzhou Dadao Bei, Guangzhou, Guangdong 510515, P.R. China

E-mail: caishaox@fimmu.com

*Contributed equally

Key words: cell adhesion molecules, epithelial cell biology, epithelial injury, inflammatory mediators in asthma, lung epithelial permeability barrier hyperpermeability and induced the disruption of junction proteins. Furthermore, HMGB1 elicited the activation of the RAGE/extracellular signal-related kinase (ERK)1/2 signaling pathway, which correlated with barrier dysfunction in the 16HBE cells. Anti-RAGE antibody and the ERK1/2 inhibitor, U0126, attenuated the HMGB1-mediated changes in barrier permeability, restored the expression levels of occludin and claudin-1 and pevented the redistribution of E-cadherin and $\beta$-catenin. Taken together, the findings of our study demonstrate that HMGB1 is capable of inducing potent effects on epithelial barrier function and that RAGE/ERK1/2 is a key signaling pathway involved in the crosstalk between formations of junction proteins and epithelial barrier dysfunction.

\section{Introduction}

Asthma is a syndrome composed of heterogeneous inflammatory disorders of the respiratory tract, characterized by airflow obstruction. The bronchial epithelium is central to the pathogenesis of asthma and plays a role in immune regulation during the initiation of allergic responses (1). Epithelial barrier function is dependent on cellular integrity, as well as on the coordinate expression and interaction of proteins in cellular junctional complexes, including apical tight junctions (TJs) and adherens junctions (AJs) (2,3). Apical TJs are mainly comprised of the interacting proteins, occludin and claudins. The AJ, comprised of E-cadherin and catenins, has been implicated in the assembly and maintenance of TJs. It has been suggested that airway epithelial barrier function is compromised in asthma. Previous findings have revealed structural abnormalities in the apical junctional complexes of asthmatics, compared with those in healthy subjects (4). The junction proteins are considered to be the gatekeepers responsible for different aspects of airway epithelial barrier function $(5,6,38)$. These structural and functional abnormalities of junction proteins may lead to enhanced signaling between the epithelium, and the underlying immune and structural cells.

High-mobility group box 1 protein (HMGB1), a nuclear DNA-binding protein, participates in a number of pathological processes. It is secreted into the extracellular milieu and functions as a pro-inflammatory cytokine (7). There is 
accumulating evidence that HMGB1 is involved in various pathological processes, including inflammatory disorders of the respiratory tract (8-10). In a previous study, we examined the expression levels of HMGB1 in plasma and induced sputum from patients with asthma and explored the association between HMGB1 and lung function (11). It has been demonstrated that HMGB1 plays a potential role in the development of asthma $(8,10,11)$; however, the exact role of HMGB1 in the pathogenesis of asthma its and mechanisms of action remain to be elucidated. Both HMGB1 and the receptor for advanced glycation end-products (RAGE) contribute to the pathogenesis of asthma (12-16). Blocking HMGB1 activity has been shown to decrease the magnitude of the allergic response in a mouse model of asthma induced by either house dust mite (HDM) extract or to ovalbumin (OVA) (12-16). RAGE knockout mice have also been shown to exhibit attenuated airway hypersensitivity, eosinophilic inflammation and airway remodeling (15). To date, to the best of our knowledge, there are no studies available on the role of the HMGB1/RAGE axis in epithelial barrier function.

Interleukin (IL)-1 $\beta$ is a prototypical, multifunctional cytokine which plays a crucial role in the inflammatory process in chronic lung diseases (17). Previous studies have reported that HMGB1 in synergy with IL-1 $\beta$ enhances pro-inflammatory responses in immune cells $(18,19)$. Furthermore, the results of one of our previous studies provided evidence that HMGB1 in synergy with IL-1 $\beta$ promoted cytokine release in the human bronchial epithelial cell line, 16HBE (20). However, available data regarding the specific effects exerted by HMGB1 in combination with IL-1 $\beta$ on epithelial barrier function are limited.

Therefore, in the present study, we aimed to examine the effects of HMGB1 on epithelial barrier structure and function, and to characterize the possible mechanisms responsible for these modulatory properties. Our findings indicated that HMGB1 not only increased barrier permeability, but also selectively disrupted the expression of occludin and claudin-1, and stimulated the redistribution of E-cadherin and $\beta$-catenin through the RAGE/extracellular signal-related kinase (ERK)1/2 signaling pathway. In addition, the presence of IL-1 $\beta$ may facilitate the HMGB1-induced dysfunction of the epithelial barrier.

\section{Materials and methods}

Epithelial cell culture. The human bronchial epithelial cell line, 16HBE14o- (16HBE), was used in this study (provided by Professor Yiguo Jiang of Guangzhou Medical University, Guangzhou,China). The 16HBE cells, a differentiated SV-40 transformed bronchial epithelial cell line, were used due to the highly characteristic intercellular adhesions [Wan et al (21)]. The 16HBE cells were cultured in 12-well Transwell inserts (Corning Costar, Corning, NY, USA) or dishes (Nest Scientific USA, Rahway, NJ, USA) coated with $30 \mathrm{~g} / \mathrm{ml}$ collagen and $10 \mathrm{~g} / \mathrm{ml}$ bovine serumalbumin(BSA) in Dulbecco's modified Eagle's medium (DMEM; Gibco Life Technology Co., Shanghai, China), containing $10 \%$ fetal calf serum (FCS; Gibco/Invitrogen, Carlsbad, CA, USA). At 80-90\% confluence, the cells were passaged and seeded at a density of $10^{4}-10^{5}$ cells/ $\mathrm{cm}^{2}$ for use in the experiments. After 4 days, confluent mono- layers of $16 \mathrm{HBE}$ cells were starved for $24 \mathrm{~h}$ in serum-free DMEM; they were then stimulated with human recombinant HMGB1 (Sigma-Aldrich, Shanghai, China) at $400 \mathrm{ng} / \mathrm{ml}$ for $0,1,6,12,24$ or $48 \mathrm{~h}$, or stimulated with HMGB1 at 100,200 and $400 \mathrm{ng} / \mathrm{ml}$ for $24 \mathrm{~h}$. The cells were also treated other mediators and inhibitors in starvation medium, namely anti-RAGE antibody $(5 \mu \mathrm{g} / \mathrm{ml}$; Merck Millipore, Darmstadt, Germany), the ERK1/2 tyrosine kinase inhibitor, U0126 (10 $\mu \mathrm{M}$; Cell Signaling Technology, Danvers, MA, USA), the PI3K tyrosine kinase inhibitor, LY294002 (25 $\mu \mathrm{M}$; Cell Signaling Technology) and the JNK kinase inhibitor, SP600125 (25 $\mu \mathrm{M}$; Cell Signaling Technology) for $6 \mathrm{~h}$ prior to stimulation with HMGB1. The cells were also treated with HMGB1 $(100 \mathrm{ng} / \mathrm{ml})$ and/or IL-1 $\beta(2.5 \mathrm{ng} / \mathrm{ml})$ to examine the synergistic effects.

Measurement of transepithelial electrical resistance (TER) and assessment of epithelial barrier function. Epithelial barrier function was assessed by measuring TER and fluorescein isothiocyanate (FITC)-dextran flux across the monolayers of cultured epithelial cells. Confluent monolayers of $16 \mathrm{HBE}$ cells, polarized at an air-liquid interface, were cultured in 12-well Transwell inserts (Corning Costar). TER was measured using a Millicell ERS-2 Epithelial Volt-Ohm meter with an STX01 electrode (Millipore Corp., Billerica, MA, USA), and the levels were normalized to those prior to stimulation with HMGB1 or medium only. FITC-dextran $4 \mathrm{kDa}$ (Sigma-Aldrich) was added to the upper chamber followed by incubation for $2 \mathrm{~h}$ at $37^{\circ} \mathrm{C}$ before the liquid from both chambers was removed. The paracellular flux was assessed by taking $100 \mu \mathrm{l}$ aliquots from both chambers to measure the real-time changes in permeability across epithelial cell monolayers. Fluorescence was measured in these samples using a fluorescent plate reader (Tecan Infinite M200; Tecan Group Ltd., Männedorf, Switzerland). The rates of FITCdextran permeability were regularized to the ratio between the cells stimulated with HMGB1 and medium only (control), which was denoted by $\mathrm{Pa} / \mathrm{Pc}$.

Immunofluorescence microscopy. Non-immune mouse immunoglobulin (Serotec, Oxford, UK) was used as a negative control. Following PBS washes, the cells were incubated with a secondary antibody, Alexa Fluor 488-goatanti-mouse (Invitrogen), for $1 \mathrm{~h}$ at room temperature, in the dark. All antibody dilutions were made with 3\% BSA/PBS at the optimal dilution, according to the manufacturer's instructions. Following further washes, the nuclear counterstain, 7-amino-actinomycin D was added, followed by incubation for $10 \mathrm{~min}$ at room temperature in the dark and further PBS washes.

The cell monolayers grown on glass bottom cell culture dishes (Nest Scientific USA) were fixed in 3\% paraformaldehyde at room temperature for $30 \mathrm{~min}$ before washing with PBS (Invitrogen). They were then incubated with $0.2 \%$ Triton X-100 in PBS for $10 \mathrm{~min}$, and rinsed again with PBS. The cells were blocked with 5\% skim milk in PBS for $2 \mathrm{~h}$. The membranes were then incubated overnight with a primary antibody at $4^{\circ} \mathrm{C}$ in PBS with $3 \%$ BSA, rabbit anti-E-cadherin (sc-7870) and rabbit anti- $\beta$-catenin (sc-7199; all from Santa Cruz Biotechnology, Santa Cruz, CA, USA). Following PBS washes, 
the cell monolayers were incubated with a secondary antibody, FITC (green)-linked anti-rabbit IgG (Invitrogen), for $1 \mathrm{~h}$ at room temperature in the dark. The cell nuclei were stained with 4',6-diamidino-2-phenylindole dihydrochloride (SigmaAldrich) for 5 min. A laser scanning confocal microscope (Olympus, Tokyo, Japan) was used to examine the distribution of E-cadherin in the 16HBE cells.

Western blot analysis. The cells were harvested and washed twice with ice-cold PBS, lysed for $30 \mathrm{~min}$ in a cell lysis buffer (KeyGen Biotech, Nanjing, China) containing a protease inhibitor, calcineurin inhibitors and PMSF; they were then centrifuged at $12,000 \mathrm{x}$ g for $15 \mathrm{~min}$ at $4^{\circ} \mathrm{C}$. The protein products were normalized and boiled with standard sodium dodecyl sulfate (SDS) sample buffer; the proteins were then subjected to SDS-polyacrylamide gel electrophoresis (PAGE) and transferred onto polyvinylidene fluoride membranes. The membranes were blocked for $2 \mathrm{~h}$ in $5 \%$ skim milk at room temperature, and incubated with primary antibodies at $4^{\circ} \mathrm{C}$ overnight. The antibodies utilized were as follows: rabbit anti-E-cadherin (sc-7870), rabbit anti- $\beta$-catenin (sc-7199), rabbit anti-occludin (sc-5562), and rabbit anti-claudin-1 (sc-28668) antibodies (from Santac Cruz Biotechnology); rabbit anti-phosphorylated (p-)p38 mitogen-activated protein kinase (MAPK) (p38) (4511), rabbit anti-total-p38 (8690), rabbit anti-p-ERK1/2 (4370), rabbit anti-total-ERK1/2 (4695), rabbit anti-p-c-Jun N-terminal kinase (JNK; 4668), rabbit anti-total-JNK (8690), rabbit anti-p-Akt (12178) and rabbit anti-total-Akt (4685) antibodies (all from Cell Signaling Technology); and mouse anti-RAGE antibody (MAB10040; from Merck Millipore, Darmstadt, Germany) After washing with TBS $0.1 \% /$ Tween-20 (Sigma-Aldrich), the membranes were incubated for $2 \mathrm{~h}$ at room temperature with a secondary antibody: an ECL-anti-rabbit or mouse IgG HRP-linked antibody from Cell Signaling Technology. The immunoreactive bands were detected using the enhanced chemiluminescence (ECL) system (Weijia Technology Co., Ltd., Guangzhou, China). The cells were treated with $400 \mathrm{ng} / \mathrm{ml}$ HMGB1 for $0,1,3,6,12,24$ and $48 \mathrm{~h}$. The protein expression of Toll-like receptor (TLR)2 (12276), TLR4 (13674), and RAGE was detected by western blot analysis.

Statistical analysis. Statistical analysis was performed using SPSS software, version 17.0. The data are expressed as the means \pm standard error (SE) and analyzed using two-way analysis of variance (ANOVA) to test for significant differences between the control and treatment time curves in the epithelial resistance measurements. In addition, the comparisons among groups were evaluated using one-way ANOVA, accompanied by a Bonferroni post hoc test for multiple comparisons. A P-value $<0.05$ was considered to indicate a statistically significant difference.

\section{Results}

HMGB1 induces an increase in ionic and macromolecular barrier permeability

Ionic barrier permeability. Initially, the effects of HMGB1 on ionic barrier permeability in monolayers of $16 \mathrm{HBE}$ cells were examined. The effects of HMGB1 on ionic barrier permeability were manifested in a concentration- and time-dependent manner. The effects on TER in the $16 \mathrm{HBE}$ cells stimulated with HMGB1 (400 $\mathrm{ng} / \mathrm{ml})$ for increasing periods of time are shown in Fig. 1A. Stimulation with HMGB1 $(400 \mathrm{ng} / \mathrm{ml})$ induced a decrease in TER, starting at $6 \mathrm{~h}$; the TER continued to gradually decrease over time, and the maximum decrease in TER was observed at $48 \mathrm{~h}$. The cells were then stimulated for $24 \mathrm{~h}$ in a culture medium containing HMGB1 at concentrations of 100, 200 or $400 \mathrm{ng} / \mathrm{ml}$. We found that stimulation with HMGB1 decreased the TER in a concentration-dependent manner. Stimulation with $400 \mathrm{ng} / \mathrm{ml}$ HMGB1 induced a more significant decline in TER than the other two lower concentrations $(\mathrm{P}<0.05$; Fig. 1C). These findings indicate that HMGB1 at a high concentration has the ability to induce marked changes in ionic barrier permeability.

Macromolecular barrier permeability. In addition to its effects on ionic barrier permeability, HMGB1 also increased macromolecular transmission. We found that stimulation with HMGB1 induced an augmentation in macromolecular permeability to FITC-labeled 4-kDa dextran. Concentration- and time-dependent changes in FITC-dextran permeability were also observed (Fig. 1B and D). The 16HBE cell monolayers, stimulated with $400 \mathrm{ng} / \mathrm{ml}$ HMGB1 for $48 \mathrm{~h}$, exhibited a $>50 \%$ increase in macromolecular permeability compared with the controls treated with medium only ( $\mathrm{P}<0.05$; Fig. 1B). HMGB1 at a concentration of $400 \mathrm{ng} / \mathrm{ml}$ exerted a significant effect on barrier permeability; hence, this concentration of HMGB1 was used in the subsequent experiments examining the mechanisms responsible for the effects of HMGB1.

HMGB1-mediated disruption in the expression and redistribution of junction proteins. To elucidate the mechanisms responsible for the HMGB1-induced barrier dysfunction, we examined whether the changes in barrier function were paralleled by changes in the expression levels of intercellular junction proteins. Firstly, we stimulated the $16 \mathrm{HBE}$ cells with 100,200 or $400 \mathrm{ng} / \mathrm{ml} \mathrm{HMGB} 1$ or culture medium for $24 \mathrm{~h}$. Only the concentration of $400 \mathrm{ng} / \mathrm{ml}$ HMGB1 had an effect on the expression of junction proteins, and it caused a significant decrease in the protein expression levels of occludin and claudin-1. However, western blot analysis revealed no significant changes in the protein levels of E-cadherin and $\beta$-catenin in the cultures stimulated with $400 \mathrm{ng} / \mathrm{ml} \mathrm{HMGB1}$ (Fig. 2A). The epithelial cell monolayers were then stimulated with $400 \mathrm{ng} / \mathrm{ml}$ HMGB1 for 1, 6, 12, 24 and $48 \mathrm{~h}$. Western blot analyses also revealed similar changes in $\mathrm{TJ}$ and adhesion junction proteins in response to stimulation with HMGB1. Western blot analysis revealed that there were no differences in the protein levels of E-cadherin and $\beta$-catenin between the HMGB1-stimulated cells and the control cells within $48 \mathrm{~h}$. However, stimulation with HMGB1 induced a time-dependent decrease in the levels of occludin and claudin-1, which was already detectable within $24 \mathrm{~h}$ of exposure in the $16 \mathrm{HBE}$ cells; a more significant decrease in these levels was observed at $48 \mathrm{~h}$ (Fig. 2B). These changes were in accordance with those observed for ion and macromolecular barrier permeability.

Surprisingly, no similar changes in the expression levels of E-cadherin and $\beta$-catenin were observed in our study. The results of western blot analysis indicated that HMGB1 had no effect on the expression of these two adhesion junction proteins in the 16HBE cells (Fig. 2A and B). However, immunofluorescence staining revealed the redistribution of E-cadherin from the cell 
A

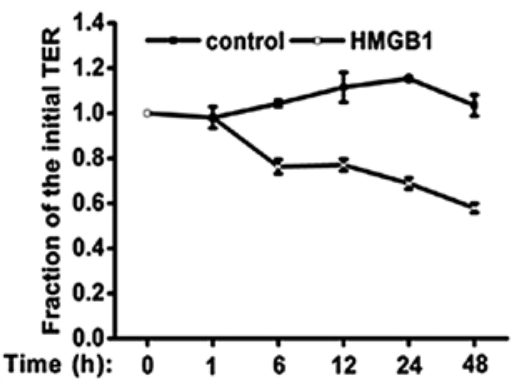

C

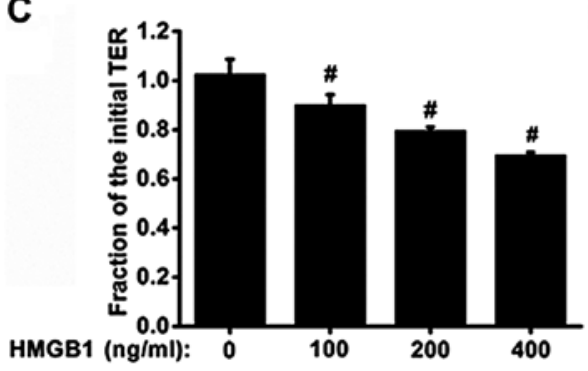

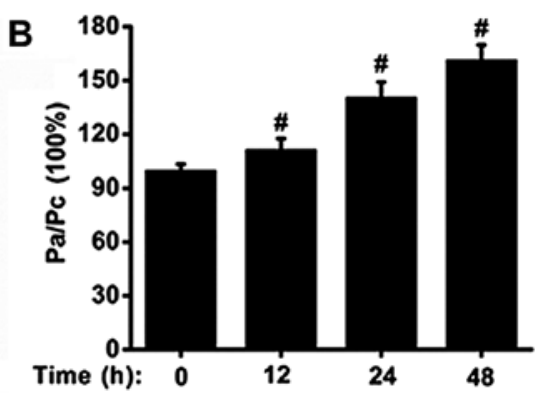

D

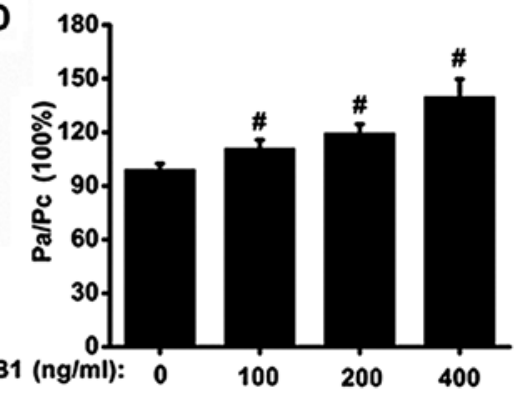

Figure 1. Time- and concentration-dependent effects of high-mobility group box 1 protein (HMGB1) on airway epithelial barrier function. 16HBE cells were seeded in 12-well Transwell inserts, grown for 3-5 days, and serum-deprived overnight. (A and B) To investigate the time-dependent effects, epithelial cell monolayers were treated with $400 \mathrm{ng} / \mathrm{ml} \mathrm{HMGB1}$ or medium only ( $\mathrm{n}=6$ experiments). (C and D) To examine the concentration-dependent effect, the epithelial cell monolayers were treated with 100, 200 and $400 \mathrm{ng} / \mathrm{ml} \mathrm{HMGB1}$, or medium for $24 \mathrm{~h}$ ( $\mathrm{n}=6$ experiments). (A and C) Transepithelial electrical resistance (TER) was measured with ERS-2, and the levels of TER were normalized to those prior to stimulation with HMGB1 or medium only (control); (B and D) the rates of FITC-dextran permeability were normalized to the ratio between HMGB1 and the medium only (control) stimulation, which was denoted by Pa/Pc. P-values were calculated using the ANOVA test. ${ }^{\prime \prime} \mathrm{P}<0.05$ vs. control.

membrane to the cell plasma and the disruption of $\beta$-catenin in the HMGB1-stimulated 16HBE cells (Fig. 2C and D), suggesting that the expression of E-cadherin and $\beta$-catenin may also be affected by HMGB1, and that the redistribution of these proteins was the principal effect.

Involvement of the RAGE/ERK cascade in HMGB1-induced barrier dysfunction and modification of junction proteins. To elucidate the mechanisms responsible for the HMGB1-induced dysfunction of the epithelial barrier, we hypothesized that HMGB1 receptors, including RAGE, TLR2 and TLR4, as well as downstream MAPK signaling, may contribute to this type of barrier dysfunction. Western blot analysis was performed to measure the expression levels of TLR2, TLR4, RAGE, downstream MAPK signaling [p38 MAPK (p38), JNK and ERK] and $\mathrm{PI} 3 \mathrm{~K} / \mathrm{Akt}$ signaling in the $16 \mathrm{HBE}$ cells stimulated with $400 \mathrm{ng} / \mathrm{ml}$ HMGB1 for different periods of time. Our results demonstrated that the expression of RAGE began to increase significantly at $1 \mathrm{~h}$, sustained a high level within $12 \mathrm{~h}$, and decreased markedly at $24 \mathrm{~h}$ following stimulatoin with HMGB1. However, no significant changes in the protein levels of TLR2 and TLR4 were observed following stimulation with HMGB1 (Fig. 3A). In line with this finding, HMGB1 increased the threonine/tyrosine phosphorylation of JNK, ERK and Akt, and this effect was noticeable at 5,6 and $7 \mathrm{~h}$, respectively (Fig. 3B).

Previous studies have reported that HMGB1 and RAGE contribute to immune and inflammatory responses $(7,10,12,13)$; thus, we hypothesized that the RAGE signaling pathway may be involved in HMGB1-induced defects in epithelial barrier function. RAGE antibody had no significant effect on resting TER or the basal permeability to FITC-dextran. As expected, pre-treatment with RAGE antibody $(5 \mu \mathrm{g} / \mathrm{ml})$ substantially attenuated the HMGB1-induced decrease in TER and the increase in FITC-dextran permeability, compared with the HMGB1stimulated group (Fig. 4A and B). We then investigated whether the inhibition of MAPK and PI3K/Akt signaling alleviates the HMGB1-induced dysfunction of the epithelial barrier. Treatment of the 16HBE cells with the ERK1/2 tyrosine kinase inhibitor, U0126, significantly reversed the HMGB1-induced changes in TER and FITC-dextran permeability (Fig. 4C and D); however, no such effects were observed when the cells were treated with the PI3K tyrosine kinase inhibitor, LY294002, and the JNK kinase inhibitor, SP600125 (Fig. 4E-H). We also found that ERK1/2 downstream signaling was dependent on RAGE, as the HMGB1-induced p-ERK1/2 response was suppressed by treatment with anti-RAGE antibody (Fig. 5A).

Treatment with the ERK1/2 tyrosine kinase inhibitor, U0126, considerably reversed the HMGB1-induced changes in TER and FITC dextran permeability; we examined its effect on the HMGB1-induced downregulation of occludin and claudin-1. Western blot analysis revealed a significant decrease in the expression of occludin and claudin-1 in the cell cultures stimulated with HMGB1; these effects were substantially inhibited by U0126 (Fig. 5B). As shown in our above-mentioned experiments, the redistribution of proteins was the principal effect of the HMGB1-induced disruption of E-cadherin and $\beta$-catenin. We assessed the distribution of adhesion junction proteins in response to HMGB1 stimulation and pre-treatment with U0126. In the control cells, immunostaining for E-cadherin and $\beta$-catenin exhibited a similar plasma membrane distribution. Although stimulation with HMGB1 promoted a loss of immunostaining for E-cadherin and the disruption of $\beta$-catenin 
A

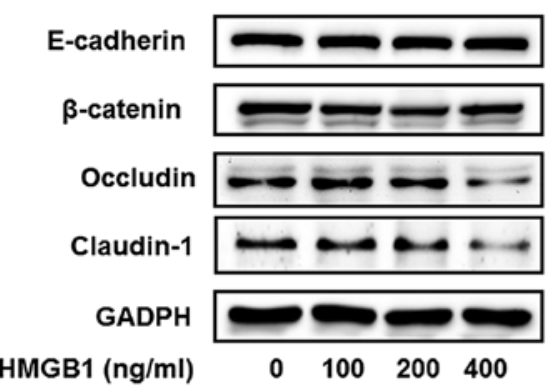

B E-cadherin

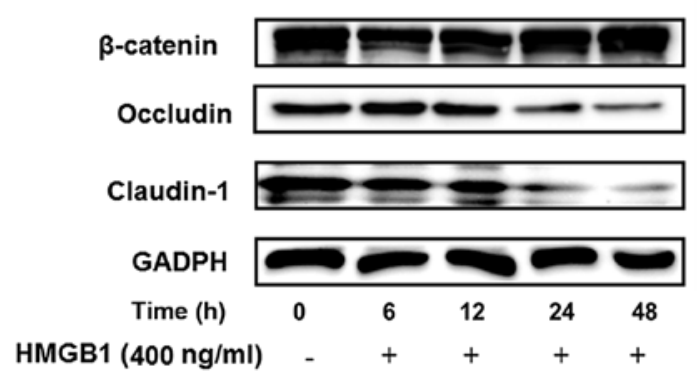

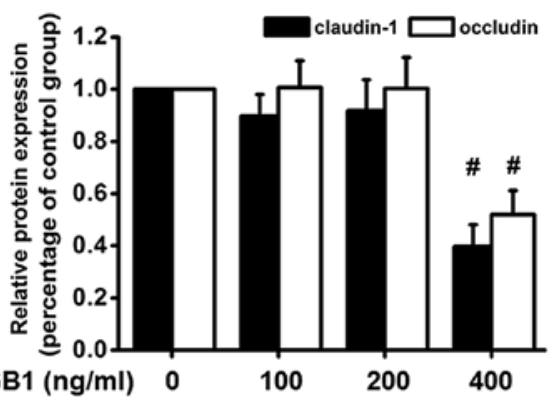

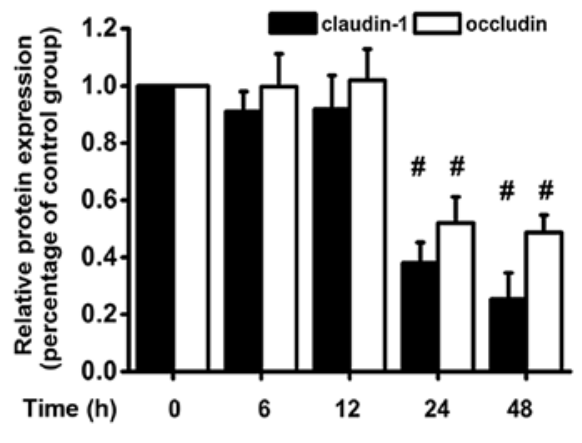

C

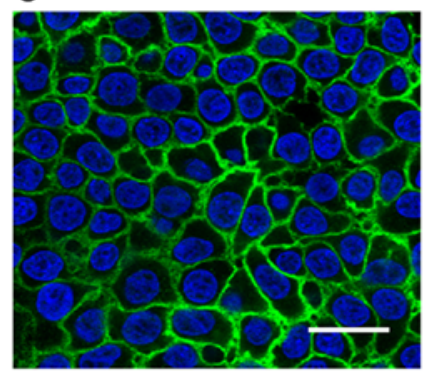

E-cadherin/Control

D

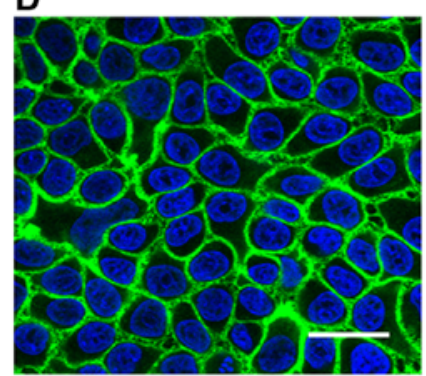

$\beta$-catenin/Control

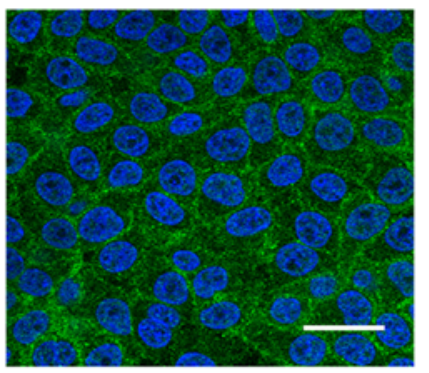

E-cadherin/ HMGB1 $100 \mathrm{ng} / \mathrm{ml}$

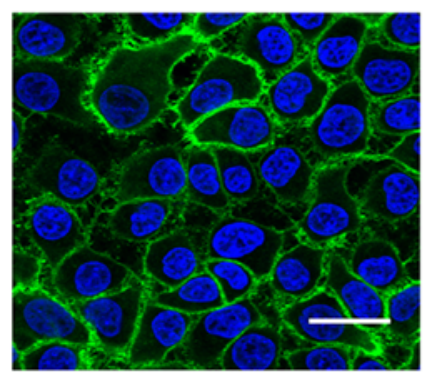

$\beta$-catenin/ HMGB1 $100 \mathrm{ng} / \mathrm{ml}$

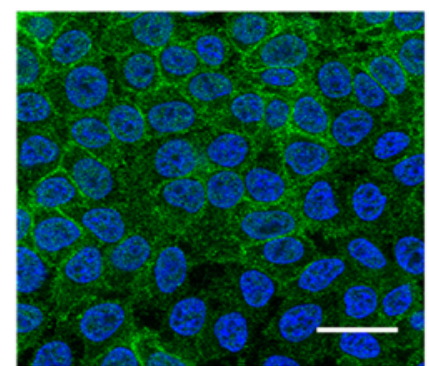

E-cadherin/ HMGB1 $400 \mathrm{ng} / \mathrm{ml}$

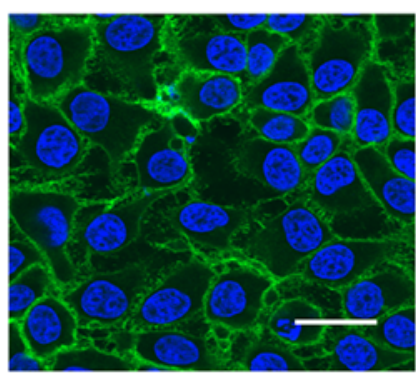

$\beta$-catenin/ HMGB1 $400 \mathrm{ng} / \mathrm{ml}$

Figure 2. High-mobility group box 1 protein (HMGB1) causes considerable changes in the expression and distribution of junction proteins. 16HBE cells were seeded in 12-well Transwell inserts, grown for 3-5 days, and serum-deprived overnight. Total cell lysates were prepared and E-cadherin, $\beta$-catenin, occludin and claudin-1 were detected by western blot analysis. (A) $16 \mathrm{HBE}$ cells were treated with 100, $200 \mathrm{or} 400 \mathrm{ng} / \mathrm{ml} \mathrm{HMGB} 1$, or with medium only for $24 \mathrm{~h}$. Only the concentration of $400 \mathrm{ng} / \mathrm{ml}$ HMGB1 induced a significant decrease in junction protein expression among the 3 concentrations used, and it selectively downregulated the expression of occludin and claudin-1. (B) 16HBE cells were stimulated with $400 \mathrm{ng} / \mathrm{ml} \mathrm{HMGB1}$ for 0, 6, 12, $24 \mathrm{or} 48 \mathrm{~h}$. Western blot analysis revealed that the expression of E-cadherin and $\beta$-catenin was unaltered following stimulation with HMGB1, and the expression levels of occludin and claudin-1 were lower following stimulation with HMGB1 for 24 and $48 \mathrm{~h}$. (C and D) 16HBE cells were exposed to 100 or $400 \mathrm{ng} / \mathrm{ml} \mathrm{HMGB1}$ or medium only for $24 \mathrm{~h}$ and E-cadherin and $\beta$-catenin were detected by immunofluorescence staining. Immunofluorescence staining revealed the redistribution of E-cadherin from the cell membrane to the cell plasma and the disruption of $\beta$-catenin in the HMGB1-stimulated $16 \mathrm{HBE}$ cells. Representatives of 3 independent experiments are displayed. Scale bar, $50 \mathrm{~mm}$. ${ }^{\sharp} \mathrm{P}<0.05 \mathrm{vs.} \mathrm{control.}$

staining at cell junctions, these effects were prevented by treatment with U0126 (Fig. 5C and D). Therefore, it is possible that RAGE/ERK1/2 signaling contributes to the HMGB1-induced dysfunction of the epithelial barrier.
HMGB1 in synergywithIL-1 $\beta$ enhances the effects on epithelial barrier dysfunction. Previous research has demonstrated that HMGB1, by forming specific complexes with damage-associated molecular patterns (DAMPs) and cytokines, has greater 


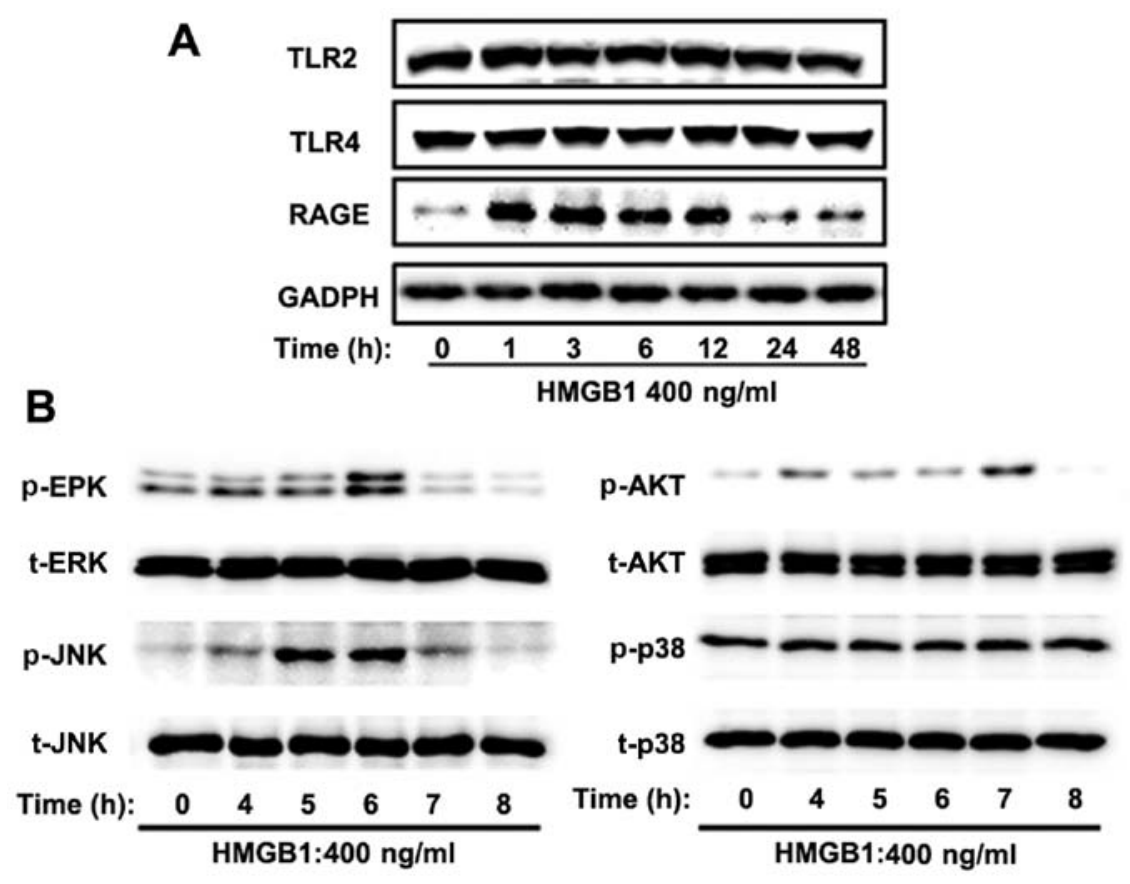

Figure 3. High-mobility group box 1 protein (HMGB1) induces the activation of the receptor for advanced glycation end-products (RAGE)/extracellular signal-regulated kinase (ERK)1/2 pathway in $16 \mathrm{HBE}$ cells. The cells were stimulated with $400 \mathrm{ng} / \mathrm{ml} \mathrm{HMGB1}$ for the indicated periods of time. (A) The protein expression of Toll-like receptor (TLR)2, TLR4 and RAGE was detected by western blot analysis. HMGB1 only increased the protein expression level of RAGE. (B) The activation of 3 mitogen-activated protein kinase (MAPK) pathways [phosphorylated (p-)MAPK/total (t-)MAPK: p-ERK, t-ERK, p-p38 MAPK (p38), t-p38, p-c-Jun N-terminal kinase (JNK) and t-JNK] and phosphatidylinositol 3-kinase (PI3K)/Akt signaling pathways ws detected by western blot analysis at the indicated time points. HMGB1 induced ERK1/2, Akt and JNK phosphorylation, but did not alter p38 phosphorylation. Representatives of the 3 independent experiments are shown.

pro-inflammatory activity than HMGB1 alone $(18,19)$. Our previous study confirmed that HMGB1 in synergy with IL-1 $\beta$ enhanced cytokine release in 16HBE cells (20). In this study, we wished to determine whether there was a similar effect on barrier function. As shown in Fig. 6A, HMGB1 (100 ng/ml) in synergy with IL-1 $\beta(2.5 \mathrm{ng} / \mathrm{ml})$ exerted a more significant effect on TER, compared to the effects observed with stimulation with HMGB1 alone. A 2-fold increase in the permeability to FITC-dextran was induced by stimulation with HMGB1 $(100 \mathrm{ng} / \mathrm{ml})$ in combination with IL-1 $\beta$, while only a slight increase in this parameter was induced by stimulation with HMGB1 alone ( $\mathrm{P}<0.05$; Fig. 6B). The synergistic effects on epithelial barrier dysfunction were also confirmed by analyzing the expression of junction proteins. Western blot analyses revealed that HMGB1 $(100 \mathrm{ng} / \mathrm{ml})$ in combination with IL-1 $\beta$ did not have a major effect on the E-cadherin and $\beta$-catenin protein expression levels over the 24 -h treatment period; however, there was a decrease in the protein expression levels of occludin and claudin-1 (Fig. 6C). Immunofluorescence staining of the16HBE cells for E-cadherin indicated a redistribution of staining from the membrane to the cytoplasm when the cells were stimulated with either HMGB1 or HMGB1 in synergy with IL-1 $\beta$ (Fig. 6D). On the other hand, the intensity of $\beta$-catenin staining at the cell junctions was reduced following stimulation with HMGB1, and junctional localization became irregular and disrupted by HMGB1 $(100 \mathrm{ng} / \mathrm{ml})$ in synergy with IL-1 $\beta$ (Fig. 6E), correlating with a functional alteration in the epithelial barrier function. These results demonstrated that the HMGB1-induced dysfunction of the epithelial barrier was enhanced by IL-1 $\beta$.

\section{Discussion}

To the best of our knowledge, this is the first study to demonstrate that HMGB1 increases the airway epithelial barrier permeability in a concentration- and a time-dependent manner, selectively downregulating the TJ proteins, occludin and claudin-1, and redistributing the $\mathrm{AJ}$ proteins, E-cadherin and $\beta$-catenin. HMGB1 in synergy with IL-1 $\beta$ further promoted the dysfunction of the epithelial barrier. Furthermore, RAGE and ERK1/2 were associated with the HMGB1-mediated disruption of intercellular junction proteins. This study demonstrated that HMGB1 damaged the airway epithelial barrier, which may contribute to the pathogenesis of asthma.

In the present study, we selected the airway epithelial cell line 16HBE to assess the effects of HMGB1 and HMGB1 in synergy with IL-1 $\beta$ on barrier properties. Compared with the effects on barrier function at different anatomic sites (22-24), HMGB1 induced extensive changes in the cell-cell contact integrity and the expression of both $\mathrm{TJ}$ and $\mathrm{AJ}$ proteins, which is similar to the findings in the model of bronchial barrier disruption induced by TNF- $\alpha$ (25). However, other cytokines such as IL-1, IL-4, IL-10 and vascular endothelial growth factor (VEGF) decrease barrier permeability function with no apparent extensive influence on junction proteins (26). The data presented herein support the view that HMGB1 is another crucial cytokine that is capable of inducing striking structural and functional effects on the function of the airway epithelial barrier in vitro.

In this study, we demonstrated that HMGB1 in synergy with IL-1 $\beta$ further enhanced the disruption of the epithelial barrier, which was in accordance with the fact that HMGB1 in combina- 
A

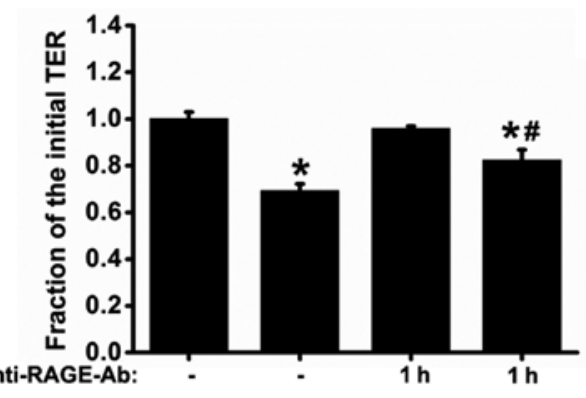

HMGB1 (400 $\mathrm{ng} / \mathrm{ml})$ :

C

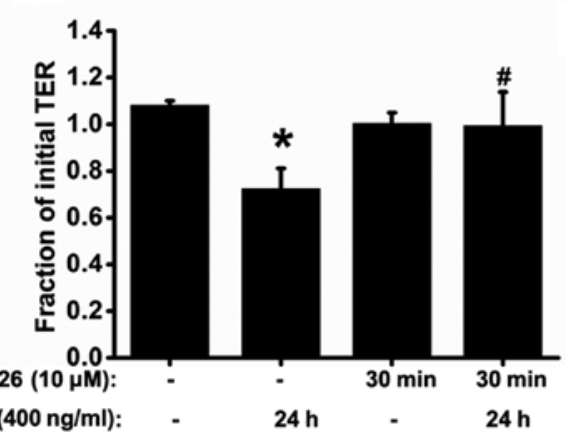

HMGB1 $(400 \mathrm{ng} / \mathrm{ml})$

E

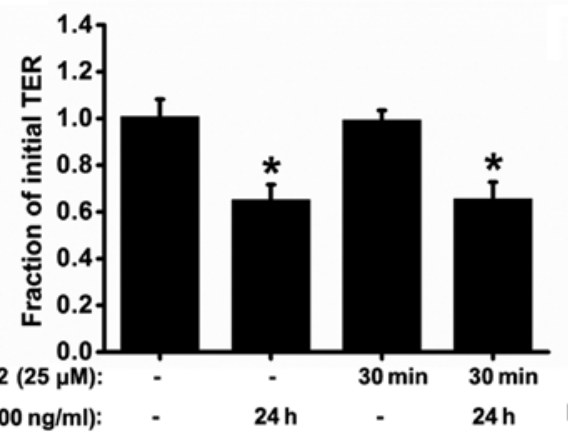

LY294002 (25 $\mu \mathrm{M})$ :

HMGB1 (400 $\mathrm{ng} / \mathrm{ml})$ :
G

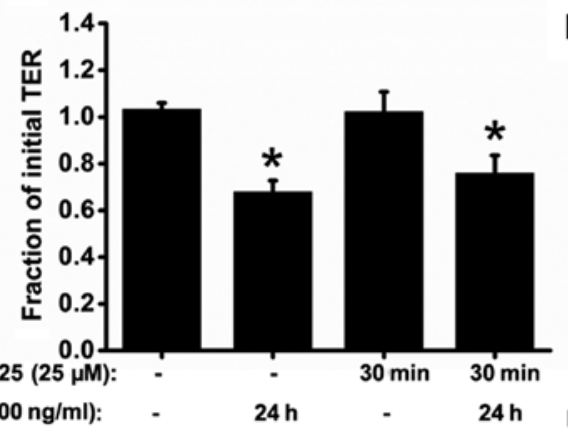

B

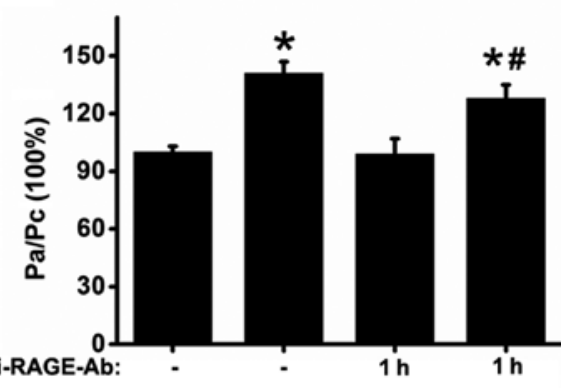

D

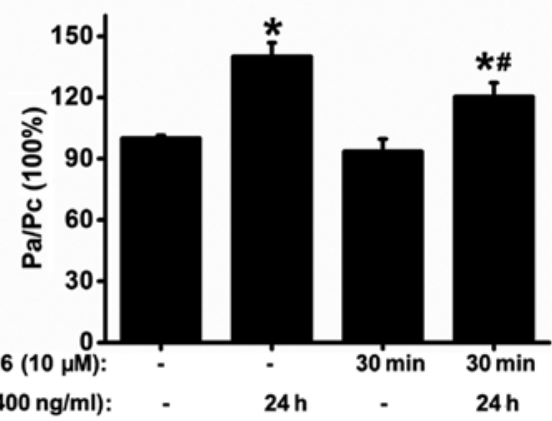

$F$

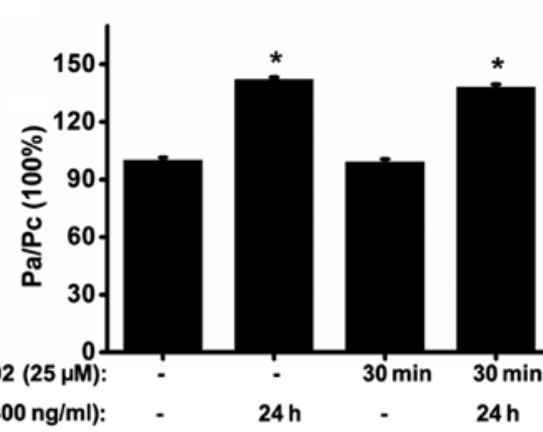

H

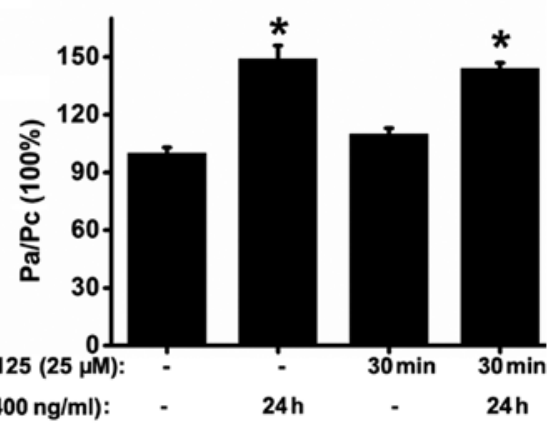

Figure 4. Blockade of the receptor for advanced glycation end-products (RAGE)/extracellular signal-regulated kinase (ERK)1/2 pathway attenuates high-mobility group box 1 protein (HMGB1)-induced epithelial barrier dysfunction in 16HBE cells. (A and B) To ascertain that the barrier dysfunction was mediated by RAGE, 16HBE cells were treated with or without anti-RAGE antibody $(5 \mu \mathrm{g} / \mathrm{ml})$ for $1 \mathrm{~h}$ prior to stimulation with $\mathrm{HMGB} 1$ for $24 \mathrm{~h}$ ( $\mathrm{n}=6 \mathrm{experiments)}$ and then the transepithelial electrical resistance (TER) and FITC-dextran permeability were measured. To determine that barrier dysfunction depended on the activation of mitogen-activated protein kinases (MAPKs) or phosphatidylinositol 3-kinase (PI3K)/Akt signaling, TER and FITC-dextran permeability were measured (n=6 experiments) after the 16HBE cells were treated with or without the related signaling inhibitors: [(C and D) U0126 (ERK inhibitor, $10 \mu \mathrm{M})$, (E and F) LY294002 (PI3K/Akt inhibitor, $25 \mu \mathrm{M}$ )], and (G and H) SP600125 (JNK inhibitor, $25 \mu \mathrm{M}$ )], prior to stimulatoin with HMGB1 for $24 \mathrm{~h}$. The levels of TER were normalized to those prior to HMGB1 or medium only (control) stimulation, and the levels of the FITC-dextran permeability were normalized to the ratio between HMGB1 and medium only (control) stimulation, which was denoted by $\mathrm{Pa} / \mathrm{Pc}$. P-values were calculated using the ANOVA test. ${ }^{*} \mathrm{P}<0.05$ vs. control; ${ }^{\#} \mathrm{P}<0.05$ vs. stimulation with $400 \mathrm{ng} / \mathrm{ml}$ HMGB1.

tion with IL-1 $\beta$ elicited the release of inflammatory cytokines more effectively than either molecule alone. Our previous study demonstrated that HMGB1 in synergy with IL-1 $\beta$ increased IL-8 expression in human airway epithelial cells (20). However, the mechanisms through which HMGB1 enhances barrier dysfunction by forming complexes remain unclear. A possible explanation for this may be that HMGB1 is required to bind the molecules which promote inflammation, such as IL- $1 \beta$, in order to enhance cytokine production, much of which was shown to play a role in maintaining epithelial barrier function.

Being a typical DAMP molecule, HMGB1 initiates cellular responses by interacting with a number of different cell surface 
A
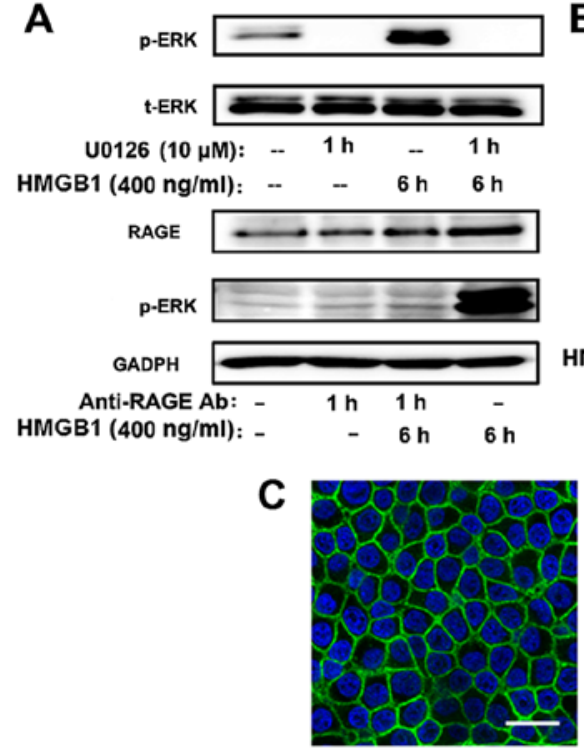

E-cadherin/Control

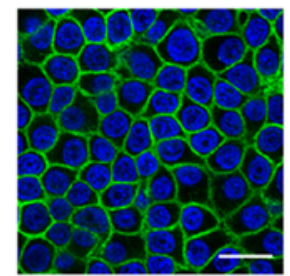

E-cadherin/ U0126
B
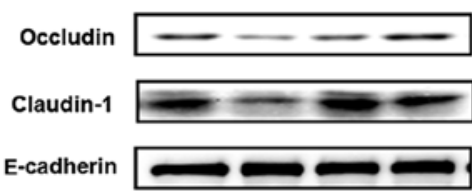

$\beta$-catenin

GADPH

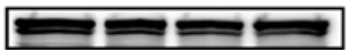

HMGB1 (400 ng/ml):

U0126 $(10 \mu \mathrm{M})$ :

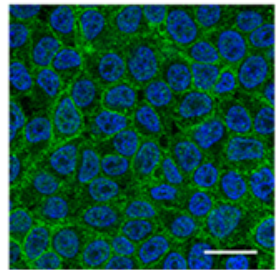

E-cadherin/HMGB1

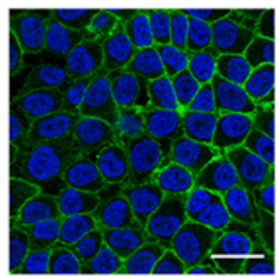

E-cadherin U0126+HMGB1

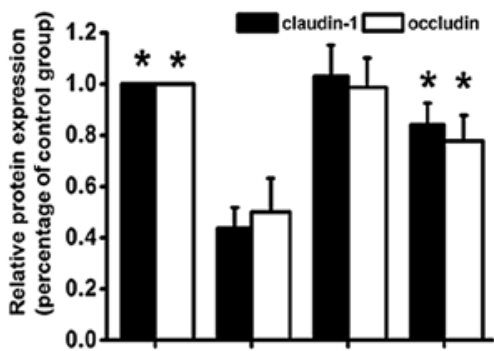

HMGB1 $(400 \mathrm{ng} / \mathrm{ml}):-24 \mathrm{~h} \quad-\quad 24 \mathrm{~h}$ U0126 $(10 \mu \mathrm{M}):-\quad-1 \mathrm{~h} \quad 1 \mathrm{~h}$
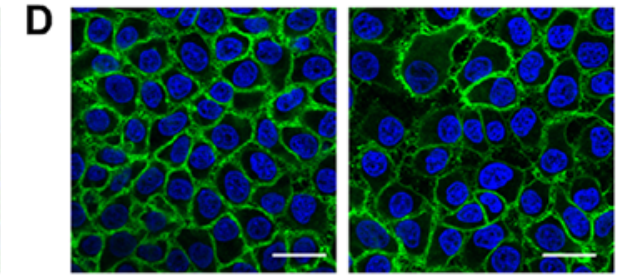

$\beta$-catenin/ Control

ß-catenin/HMGB1

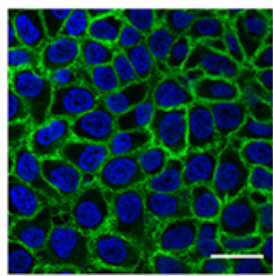

$\beta$-catenin/ U0126

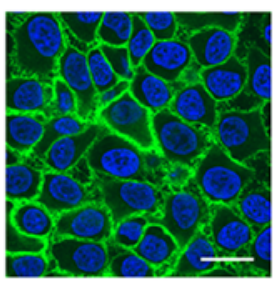

$\beta$-catenin

U0126+HMGB1

Figure 5. Activation of the receptor for advanced glycation end-products (RAGE)/extracellular signal-regulated kinase (ERK)1/2 pathway by high-mobility group box 1 protein (HMGB1) is involved in the disruption of the epithelial intercellular contacts. The $16 \mathrm{HBE}$ cells were exposed to $400 \mathrm{ng} / \mathrm{ml} \mathrm{HMGB} 1$ for the indicated periods of time. (A) 16HBE cells were treated with or without U0126 (ERK inhibitor, $10 \mu \mathrm{M}$ ), prior to stimulation with HMGB1 for $6 \mathrm{~h}$, phosphorylated (p-)ERK, and the total (t-)ERK were detected by western blot analysis. To confirm the association between RAGE and the activation of the ERK1/2 pathway, the 16HBE cells were treated with or without anti-RAGE antibody $(5 \mu \mathrm{g} / \mathrm{ml})$ for $1 \mathrm{~h}$ prior to stimulation with HMGB1 for $6 \mathrm{~h}$. The anti-RAGE antibody suppressed the HMGB1-induced p-ERK1/2; the response was verified by western blot analysis. (B) E-cadherin, $\beta$-catenin, occludin and claudin- 1 were detected using western blot analysis. U0126 inhibited the HMGB1-mediated downregulation of the tight junction proteins, occludin and claudin-1. The ERK inhibitor, U0126, prevented the delocalization of (C) E-cadherin and (D $\beta$-catenin in response to HMGB1, verified by immunofluorescence staining. Representatives of 3 independent experiments are shown. ${ }^{*} \mathrm{P}<0.05$ vs. HMGB1-stimulated group; scale bar, $50 \mathrm{~mm}$.

receptors, such as TLR2, TLR4 and RAGE (27). In the present study, the expression of RAGE was upregulated in response to HMGB1. However, no changes were observed in the expression of TLR2 and TLR4. In line with the results of our study, the blockade of RAGE with anti-RAGE antibody reduced the epithelial barrier hyperpermeability induced by HMGB1, suggesting that RAGE may be involved in the HMGB1-induced barrier disruption.

The MAPK-ERK1/2 pathway plays key roles in the aberrant distribution of E-cadherin in models of HDM- or cigarette smoke extract-induced epithelial disruption (28-30); this evidence was also supported by the findings of our previous study using an animal model of toluene diisocyanate (TDI)induced asthma (31). In the present study, we also showed that U0126, an ERK1/2 inhibitor, significantly inhibited the HMGB1-induced disruption of the airway epithelial barrier. Furthermore, the HMGB1-mediated phosphorylation of ERK1/2 may be prevented by the suppression of RAGE activity, using an anti-RAGE IgG. These data support the assumption that the RAGE/ERK1/2 pathway may be a key factor in the crosstalk between the formation of junction proteins and epithelial permeability barrier dysfunction.
Notably, in this study, U0126 also enhanced the expression of the TJ proteins, occludin and claudin- 1 . The reason for this remains unclear; however, ERK1/2 has been shown to interact with the $\mathrm{C}$-terminal region of occludin and to mediate the $\mathrm{H}_{2} \mathrm{O}_{2}$-induced disruption of TJs (32).

To date, the role of HMGB1 in asthma has been considered complex, and much remains to be clarified. HMGB1 displays a wide range of immunological roles in addition to its cytokineinducing effects, and may thus be considered as an alarm that alerts the human defense system of an impending danger (33). In the present study, the bronchial epithelium was highlighted as a crucial target of HMGB1. The dysregulation of junctional complex proteins, such as E-cadherin and occludin, may help to modulate the immune responses (34-37). In addition, blocking the function of E-cadherin reduced the TER, perturbing TJ formation in Madin Darby canine kidney (MDCK I) monolayers (38). Therefore, the changes in the integrity of both TJs and AJs, induced by HMGB1 may be an 'early event', and may facilitate the entry of inhaled microorganisms, irritants and allergens through the epithelium, making an important contribution to asthma exacerbations. The findings from the study by Ferhani et al (10) indicated that bronchial epithelial cells 
A

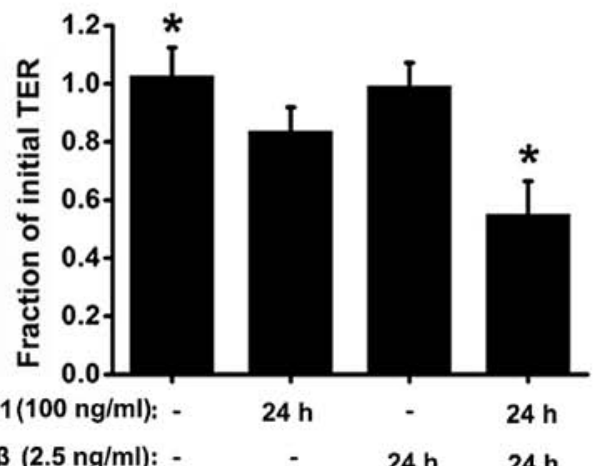

B

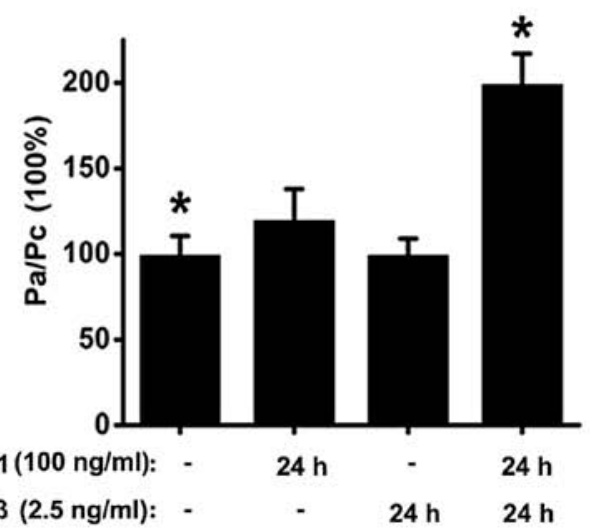

C

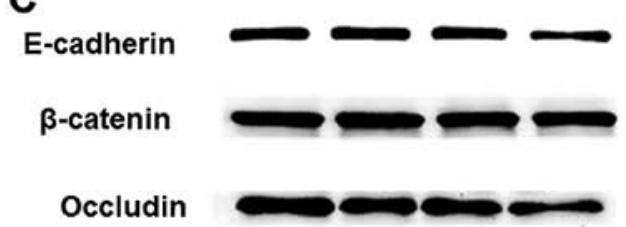

Claudin-1

GADPH

HMGB1 (100 ng/ml):

IL-1及 $(2.5 \mathrm{ng} / \mathrm{ml})$ : -

D

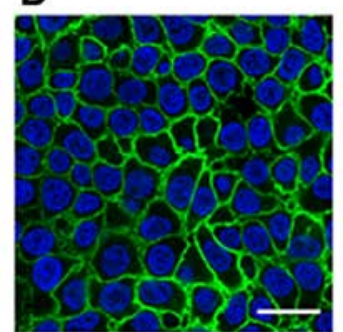

E-cadherin/Control

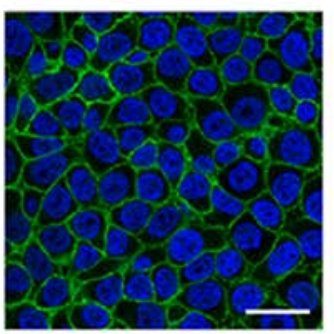

E-cadherin/ IL-1 $\beta$

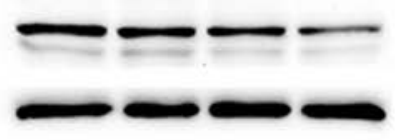

$4 \mathrm{~h}$

- $24 \mathrm{~h} 24 \mathrm{~h}$

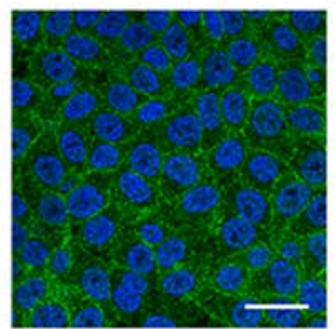

E-cadherin/HMGB1

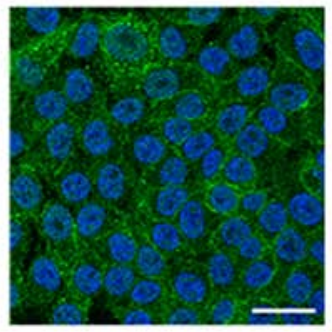

E-cadherin IL-1 $\beta+$ HMGB1

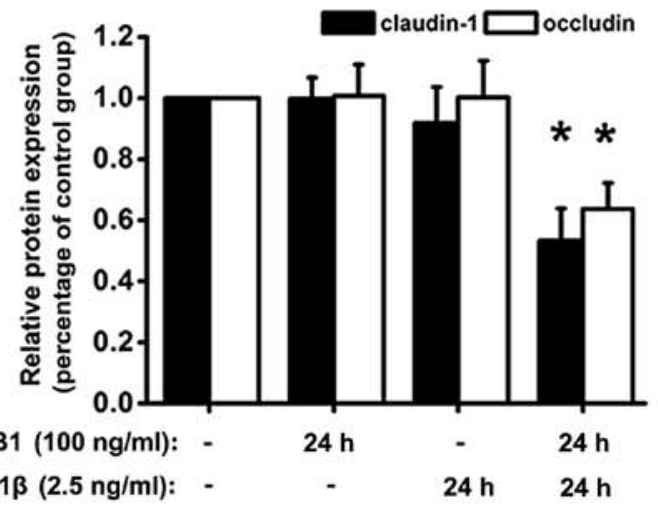

E
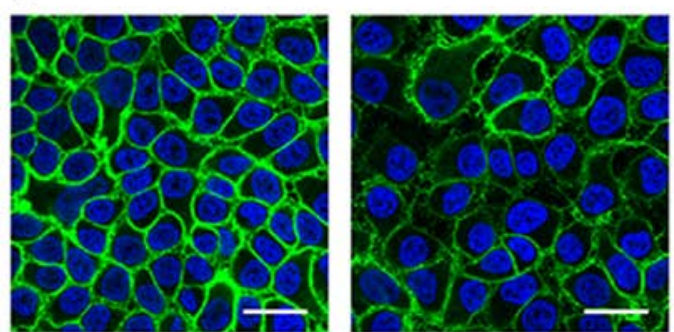

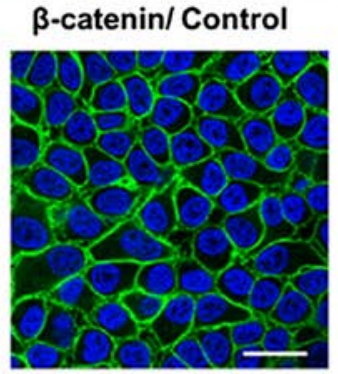

$\beta$-catenin/IL-1 $\beta$

\section{$\beta$-catenin/ HMGB1}

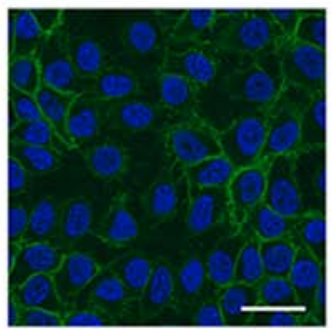

$\beta$-catenin

IL-1 $\beta+$ HMGB1

Figure 6. High-mobility group box 1 protein (HMGB1) in synergy with interleukin (IL)-1 $\beta$ enhances epithelial barrier dysfunction. 16HBE cells were stimulated with $100 \mathrm{ng} / \mathrm{ml} \mathrm{HMGB1}$ in the presence or absence of $2.5 \mathrm{ng} / \mathrm{ml} \mathrm{IL-1 \beta}$ for $24 \mathrm{~h}$. (A) Transepithelial electrical resistance (TER) and (B) FITC-dextran permeability were measured after 24 -h exposure to the indicated treatments ( $n=6$ experiments). (C) E-cadherin, $\beta$-catenin, occludin and claudin-1 were detected by western blot analysis. The delocalization of (D) E-cadherin and (E) $\beta$-catenin was shown by immunofluorescence staining. Representatives of 3 independent experiments are shown. The levels of TER were normalized to those prior to HMGB1 or medium (control) stimulation, and the levels of FITC-dextran permeability were normalized to the ratio between HMGB1 and medium only (control) stimulation, which was denoted by Pa/Pc. P-values were calculated using an ANOVA test. ${ }^{*} \mathrm{P}<0.05$, vs. stimulation with $100 \mathrm{ng} / \mathrm{ml}$ HMGB1; scale bar, $50 \mathrm{~mm}$.

are important cellular sources of the high levels of HMGB1 in patients with chronic obstructive pulmonary disease. These data suggest the possibility of an autocrine interaction between HMGB1 and the bronchial epithelium, an area we intend to explore in future studies.
In conclusion, in the present study, we confirmed that HMGB1 may damage the airway epithelial barrier, and this damage may be further aggravated by IL-1 $\beta$; the HMGB1induced activation of the RAGE/ERK $1 / 2$ pathway may participate in this irregularity. Our results provide new insight 
into the mechanisms responsible for the effects of HMGB1 in lung diseases.

\section{Acknowledgements}

The present study was supported by the National Natural Science Foundation of China (grant nos. 81270087, 81270089 and 81470228); the National Program on Key Basic Research Project (973 program, no. 2012CB518203); the Industry-Academia Collaborative Project of Guangdong province and the Ministry of Education (no. 2012B091100153); the President Foundation of Nanfang Hospital, Southern Medical University (no. 2013C014).

\section{References}

1. Holgate ST, Roberts G, Arshad HS, Howarth PH and Davies DE: The role of the airway epithelium and its interaction with environmental factors in asthma pathogenesis. Proc Am Thorac Soc 6: 655-659, 2009.

2. Bazzoni G: Pathobiology of junctional adhesion molecules. Antioxid Redox Signal 15: 1221-1234, 2011.

3. Steed E, Balda MS and Matter K: Dynamics and functions of tight junctions. Trends Cell Biol 20: 142-149, 2010.

4. Xiao C, Puddicombe SM, Field S, Hay wood J, Broughton-Head V, Puxeddu I, Haitchi HM, Vernon-Wilson E, Sammut D, Bedke N, et al: Defective epithelial barrier function in asthma. J Allergy Clin Immunol 128: 549-556 e541-512, 2011.

5. Baum B and Georgiou M: Dynamics of adherens junctions in epithelial establishment,maintenance, and remodeling. J Cell Biol 192: 907-917, 2011.

6. Gumbiner B and Simons K: A functional assay for proteins involved in establishing an epithelial occluding barrier: identification of a uvomorulin-like polypeptide. J Cell Biol 102 457-468, 1986

7. Castiglioni A, Canti V, Rovere-Querini P and Manfredi AA: High-mobility group box 1 (HMGB1) as a master regulator of innate immunity. Cell Tissue Res 343: 189-199, 2011.

8. Straub C, Midoro-Horiuti T, Goldblum R, Pazdrak K and Kurosky A: Elucidating the role of high mobility group box 1 (HMGB1) cytokine in a murine model of allergic asthma. J Allergy Clin Immunol 125: AB108, 2010.

9. Kanazawa H, Tochino Y, Asai K, Ichimaru Y, Watanabe T and Hirata K: Validity of HMGB1 measurement in epithelial lining fluid in patients with COPD. Eur J Clin Invest 42: 419-426, 2012.

10. Ferhani N, Letuve S, Kozhich A, Thibaudeau O, Grandsaigne M, Maret M, Dombret MC, Sims GP, Kolbeck R, Coyle AJ, et al: Expression of high-mobility group box 1 and of receptor for advanced glycation end products in chronic obstructive pulmonary disease. Am J Respir Crit Care Med 181: 917-927, 2010.

11. Hou C, Zhao H, Liu L, Li W, Zhou X, Lv Y, Shen X, Liang Z, Cai S and Zou F: High mobility group protein B1 (HMGB1) in asthma: Comparison of patients with chronic obstructive pulmonary disease and healthy controls. Mol Med 17: 807-815, 2011.

12. Ullah MA, Loh Z, Gan WJ, Zhang V, Yang H, Li JH, Yamamoto Y, Schmidt AM, Armour CL, Hughes JM, et al: Receptor for advanced glycation end products and its ligand high-mobility group box-1 mediate allergic airway sensitization and airway inflammation. J Allergy Clin Immunol 134: 440-450, 2014.

13. Milutinovic PS, Alcorn JF, Englert JM, Crum LT and Oury TD: The receptor for advanced glycation end products is a central mediator of asthma pathogenesis. Am J Pathol 181: 1215-1225, 2012.

14. Di Candia L, Saunders R and Brightling CE: The RAGE against the storm. Eur Respir J 39: 515-517, 2012.

15. Lee CC, Lai YT, Chang HT, Liao JW, Shyu WC, Li CY and Wang CN: Inhibition of high-mobility group box 1 in lung reduced airway inflammation and remodeling in a mouse model of chronic asthma. Biochem Pharmacol 86: 940-949, 2013.

16. Shim EJ, Chun E, Lee HS, Bang BR, Kim TW, Cho SH, Min KU and Park HW: The role of high-mobility group box-1 (HMGB1) in the pathogenesis of asthma. Clin Exp Allergy 42: 958-965, 2012.

17. Mitroulis I, Skendros P and Ritis K: Targeting IL-1beta in disease; The expanding role of NLRP3 inflammasome. Eur J Intern Med 21: 157-163, 2010.

18. Sha Y, Zmijewski J, Xu Z and Abraham E: HMGB1 develops enhanced proinflammatory activity by binding to cytokines J Immunol 180: 2531-2537, 2008.
19. Bianchi ME: HMGB1 loves company. J Leukoc Biol 86: 573-576, 2009.

20. Zhang D, Zhao H, Zhou L, Song J, Dong H, Zou F and Cai S: High-mobility group box protein 1 in synergy with interleukin-1 $\beta$ promotes interleukin-8 expression in human airway epithelial cells in vitro. Nan Fang Yi Ke Da Xue Xue Bao 32: 1764-1767, 2012 (In Chinese).

21. Wan H, Winton HL, Soeller C, Stewart GA, Thompson PJ, Gruenert DC, Cannell MB, Garrod DR and Robinson C: Tight junction properties of the immortalized human bronchial epithelial cell lines Calu-3 and 16HBE14o-. Eur Respir J 15: 1058-1068, 2000

22. Sappington PL, Yang R, Yang H, Tracey KJ, Delude RL and Fink MP: HMGB1 B box increases the permeability of Caco-2 enterocytic monolayers and impairs intestinal barrier function in mice. Gastroenterology 123: 790-802, 2002.

23. Wolfson RK, Chiang ET and Garcia JG: HMGB1 induces human lung endothelial cell cytoskeletal rearrangement and barrier disruption. Microvasc Res 81: 189-197, 2011.

24. Huang W, Liu Y, Li L, Zhang R, Liu W, Wu J, Mao E and Tang Y: HMGB1 increases permeability of the endothelial cell monolayer via RAGE and Src family tyrosine kinase pathways. Inflammation 35: 350-362, 2012.

25. Hardyman MA, Wilkinson E, Martin E, Jayasekera NP, Blume C, Swindle EJ, Gozzard N, Holgate ST, Howarth PH, Davies DE and Collins JE: TNF-alpha-mediated bronchial barrier disruption and regulation by src-family kinase activation. J Allergy Clin Immunol 132: 665-675 e668, 2013.

26. Walsh SV, Hopkins AM and Nusrat A: Modulation of tight junction structure and function by cytokines. Adv Drug Deliv Rev 41: 303-313, 2000.

27. Yanai H, Ban T and Taniguchi T: High-mobility group box family of proteins: ligand and sensor for innate immunity. Trends Immunol 33: 633-640, 2012.

28. Heijink IH, Kies PM, Kauffman HF, Postma DS, van Oosterhout AJ and Vellenga E: Down-regulation of E-cadherin in human bronchial epithelial cells leads to epidermal growth factor receptor-dependent Th2 cell-promoting activity. J Immunol 178: 7678-7685, 2007.

29. Heijink IH, van Oosterhout A and Kapus A: Epidermal growth factor receptor signalling contributes to house dust mite-induced epithelial barrier dysfunction. Eur Respir J 36: 1016-1026, 2010.

30. Petecchia L, Sabatini F, Varesio L, Camoirano A, Usai C, Pezzolo A and Rossi GA: Bronchial airway epithelial cell damage following exposure to cigarette smoke includes disassembly of tight junction components mediated by the extracellular signal-regulated kinase 1/2 pathway. Chest 135: 1502-1512, 2009.

31. Song J, Zhao H, Dong H, Zhang D, Zou M, Tang H, Liu L, Liang Z, Lv Y, Zou F and Cai S: Mechanism of E-cadherin redistribution in bronchial airway epithelial cells in a TDI-induced asthma model. Toxicol Lett 220: 8-14, 2013.

32. Kevil CG, Oshima T, Alexander B, Coe LL and Alexander JS: $\mathrm{H}_{2} \mathrm{O}_{2}$-mediated permeability: role of MAPK and occludin. Am J Physiol Cell Physiol 279: C21-C30, 2000.

33. Lotze MT and Tracey KJ: High-mobility group box 1 protein (HMGB1): nuclear weapon in the immune arsenal. Nat Rev Immunol 5: 331-342, 2005.

34. Nawijn MC, Hackett TL, Postma DS, van Oosterhout AJ and Heijink IH: E-cadherin: gatekeeper of airway mucosa and allergic sensitization. Trends Immunol 32: 248-255, 2011.

35. Lambrecht BN and Hammad H: The airway epithelium in asthma. Nat Med 18: 684-692, 2012.

36. Pantano C, Ather JL, Alcorn JF, Poynter ME, Brown AL, Guala AS, Beuschel SL, Allen GB, Whittaker LA, Bevelander M, et al: Nuclear factor-kappaB activation in airway epithelium induces inflammation and hyperresponsiveness. Am J Respir Crit Care Med 177: 959-969, 2008

37. Wachtel M, Bolliger MF, Ishihara H, Frei K, Bluethmann H and Gloor SM: Down-regulation of occludin expression in astrocytes by tumour necrosis factor (TNF) is mediated via TNF type-1 receptor and nuclear factor-kappaB activation. J Neurochem 78: 155-162, 2001.

38. West MR, Ferguson DJ, Hart VJ, Sanjar S and Man Y: Maintenance of the epithelial barrier in a bronchial epithelial cell line is dependent on functional E-cadherin local to the tight junctions. Cell Commun Adhes 9: 29-44, 2002. 